\title{
Comparison Study of Water Quality Produced from a Conventional Water Treatment Plant and a Number of Compact Units
}

\author{
Hadeel Ali Al Saleh ${ }^{1}$ \\ 1 Civil Engineering Department, College of Engineering, University of Babylon, Iraq \\ Email: eng.hadeel.ali@uobabylon.edu.iq
}

\begin{abstract}
Water is very plentiful through the planet in general. Nevertheless, clean drinking water is not always accessible in the proper time or place for sufficient public or ecological use. The water significance is emphasized by the fact that in the past, great cultures have arisen near and along water bodies. Water quality of some purification complexes (compact units) in the Babylon Province (13 compact unit) as compared with Al-Hillah Al Mouahad Project (water treatment plant) was assessed by the Water Quality Index (WQI) methodology. WQI offers a particular number that states the overall water quality at a definite place and period based on many parameters concerning the quality of water. The water produced from the compact units was classified as "good water" according to the WQI classification with the values ranging from 85.4 in Bermana unit to 99.17 in Al-Muamera compact unit. Moreover, the research results showed that the water purification complexes work with efficiency, very close to the performance of large water purification projects and stations, and this means that it is possible to rely on them to obtain good drinking water quality, especially in small or remote areas.
\end{abstract}

Keywords: water quality, compact units, quality index, purification, contamination.

\section{INTRODUCTION}

Water is crucial to the survival of all living species, but this valuable resource is constantly endangered as residential communities expand. Consequently, the demand for good water quality is increased so there is a globally increased interest in providing safe water for different uses like drinking, irrigation and industrial uses and economic activities. In the last two decades, the Iraq water supplies have experienced considerable stress in terms of water quantity due to numerous causes, such as the Tigris and Euphrates dams in the neighboring countries, the global climate change and the extreme decline in annual rainfall in the region and insufficient water use planning in Iraq [Rahi \& Halihan, 2010]. Any material (either natural or man-made) can become a pollutant only if it is added at a degree or in a way that disrupts the normal functioning of the environment or impacts human or animal health.
The package technology provides an alternative to in-ground traditional treatment plants. The package method procedures are not entirely distinct from other treatment processes; however, some package plant models include creative treatment features, such as adsorption clarification. Compact drinking water plants are built to provide clean drinking water from a broad domain of water supplies in regions with insufficient and/or polluted water.

Water Quality Index (WQI) is a powerful and distinctive measure of the entire state the quality of water in a monocular expression that is useful to select the suitable management and treatment strategies to encounter the interested issues [Tyagi et al., 2013].

Various data on water quality can be gathered into a comprehensive index. WQI is a familiar technique; furthermore, it is one of the most important instruments for quality assurance of water, offering a clear measurement and delivering facts on water quality to the people and decision 
makers concerned. Thus, it turns out to be a significant factor to evaluate and manage water resources [Toma, 2013].

Al-Mansori, 2017, described the efforts to create the Shatt-Al-Hillah River Water Quality Index (WQI) that can be used to determine the overall quality of water for the major Iraqi rivers and streams for public use along its entire stretch. The index introduced in this study consists of seven quantifiable parameters [Al-Mansori, 2017].

Mohamed et al., 2012, measured the quality of water in several water stations in the Kingdom of Saudi Arabia by using the WQI approach. In general, the findings obtained have shown that the water is of good quality at most sites, also WQI could be adapted as a method to measure and compare the quality of water from various sources. It provides a general understanding of the potential water issues in a given region [Mohamed et al., 2012].

Al Saleh, 2014, presented a study on the consistency of the river Euphrates as potable water by creating WQI for some water quality-monitoring stations along the river Euphrates. The study showed that the best level of water quality was rated "excellent" in January and February, whereas the lowest water quality rated as "poor" was in September 2007 and June 2013 over the entire study time [Al Saleh, 2014].

The goal of the present paper was to apply the WQI approach to evaluate the performance efficiency of some purification complexes (compact units) in the Babylon Province (13 compact unit) ,as compared with Al-Hillah Al Mouahad Project (conventional water treatment plant) on the $\mathrm{Eu}-$ phrates River (Raw \& treated water) during the period from 2012 to 2014, for the determination of its water convenience for the drinking and irrigation purposes.

\section{Water Quality Index}

The transformation of data relating water quality into the information that can be readily interpreted and accessed by the community is the main objective of applying the water quality index. The complete description of water quality cannot be represented by a solitary number because of the absence of other parameters in the index. However, an index of water quality built on certain very significant criteria will offer a basic measure of water quality [Mohamed et al., 2012, Al-Mansori, 2017].
Indices are constructed on the values of numerous physical, chemical and biological factors in a sample of water. Applying the indices in monitoring systems to measure the health of ecosystems enables notifying the general public and decision-makers about the status of the ecological system [Simoes et al., 2008]. The water quality indices are instruments for assessing water quality levels. The development of the WQI includes three key phases [US EPA, 2009]:

1) For obtaining assessments of the individual water quality measures;

2) Transform the measurements into 'sub-index' values to represent them on a regular scale;

3) Add the individual sub-index values to the aggregate sum of the WQI.

The Water Quality Index is known to be one of the most important tools for delivering the water quality knowledge to the people and the decision makers concerned. It is now becoming an important criterion for the estimation and control of water supplies.

\section{Package (Compact) Water Treatment Plant}

Compact water treatment facilities are provided to small societies and sites which do not have the access to a major water treatment plant. Units are usually mounted along a source of surface water. The units are assembled in a polished, mild steel structure ready to be mounted upon arrival to the location. Standard capacities vary from 5 to $200 \mathrm{~m}^{3} / \mathrm{h}$. Multiple units are usually applied for larger structures. These systems require limited civil works or site arrangements; they are simply delivered by regular trucks, immediately installed on site. Limited water treatment plants also find it hard to comply with the water quality standards set down by the United States EPA [US EPA, 2009].

Small societies also face budgetary limitations in the procurement and operation of traditional treatment systems. Their issues can be further compounded if they do not have the services of full-time, skilled operators. These units are most commonly used for the management of surface water sources for the elimination of turbidity, color and coliform species with filtration processes. However, there are also other treatment technologies applicable to small schemes as packed plants. These technologies or a mixture of them may be integrated into the packaging plant to provide extensive water treatment. 
Package Water Treatment Plants comprise of the Following Components:

- Raw water intake pumps,

- Disinfection and coagulation systems,

- Flocculation tank,

- Clarifier,

- Filtration tank,

- Backwash pumps,

- Blowers for sand filter air-scour,

- Pressure type sand filters,

- RO unit (Skid mounted),

- Interconnecting piping.

\section{MATERIALS AND METHOD}

\section{Sample collection and analysis}

The water quality data for 13 water purification units and one water purification plant (AlTaiara, Al-Ataej, Wardia1, Wardia2, Athar Babil, Muamera, Al-Nekhala, Al-Dolab, Al-Ifar, Barnoon1, Annana2, Al-Jimejma, Bermana, Al-Hillah Al Mouahad Project) were collected for the period (2012-2014). The water samples were then analyzed for 13 parameters: Turbidity (TUR), $\mathrm{pH}$, Electrical Conductivity (EC), Alkalinity (ALK), Hardness (TH), Calcium (Ca), Magnesium (Mg), Chloride $(\mathrm{Cl})$, Solids, Sulphate $\left(\mathrm{SO}_{4}\right)$, Total Dissolve Temperature (TDS), Total Suspended Solids (TSS), Sodium (Na) and Potassium (K) using standard procedures recommended by APHA.

\section{Methodology}

The approach includes the creation of the Water Quality Index model for the measurement of water quality. Three measures are followed for WQI computation. In the first step, each of the 13 parameters was given a weight $\left(w_{i}\right)$ based on its relative significance in the overall quality of drinking water (see Table 1). The full weight of 4 has been allocated to the $\mathrm{pH}, \mathrm{SO}_{4}$ and TDS parameters because of their key importance in the measurements of water quality. In the second step, the relative weight $\left(W_{i}\right)$ is determined from the equation below [Ramakrishnaiah et al., 2009].

$$
W_{i}=\frac{w_{i}}{\sum_{k=1}^{n} w_{k}}
$$

where: $W_{i}$ is the relative weight,

$w_{i}$ is the weight of each variable,

$n$ is the number of variables.
Values of the determined relative weights $\left(W_{i}\right)$ of the parameters are shown in Table 1.

In the third step, each parameter is assigned with quality rating scale $\left(q_{i}\right)$ by dividing its concentration in each water sample by its corresponding standard giving by the guidelines and multiplied the result by 100 as in equation 2 :

$$
q_{i}=\left(\frac{C_{i}}{s_{i}}\right) \times 100
$$

where: $q_{i}$ is the quality rating based on concentration of the $i^{\text {th }}$ parameter,

$C_{i}$ is the concentration of each chemical parameter in each water sample in $\mathrm{mg} / \mathrm{l}$, $S_{i}$ is the Iraqi drinking water standard for each chemical parameter in $\mathrm{mg} / \mathrm{l}$.

For the computation of the WQI, at first, the SI is calculated for all the chemical parameters separately, and is then used to calculate the WQI according to equations 3 and 4 .

$$
\begin{gathered}
S I_{i}=W_{i} \times q_{i} \\
W Q I=\sum_{i=1}^{n} S I_{i}
\end{gathered}
$$

where: $S I_{i}$ is the sub-index of the $i^{\text {th }}$ parameter, $n$ is the number of parameters.

Table 1. Relative weights of chemical parameters

\begin{tabular}{|c|c|c|c|}
\hline Parameter & $\begin{array}{c}\text { Weights } \\
\left(w_{i}\right)\end{array}$ & $\begin{array}{c}\text { Iraqi } \\
\text { Standards }\end{array}$ & $\begin{array}{c}\text { Relative weight } \\
\left(W_{i}\right)\end{array}$ \\
\hline TUR & 2 & 5 & 0.06060606 \\
\hline $\mathrm{Ph}$ & 4 & $6.5-8.5$ & 0.12121212 \\
\hline $\mathrm{EC}$ & 2 & 250 & 0.06060606 \\
\hline $\mathrm{ALK}$ & 3 & 200 & 0.09090909 \\
\hline $\mathrm{TH}$ & 2 & 500 & 0.06060606 \\
\hline $\mathrm{Ca}$ & 2 & 150 & 0.06060606 \\
\hline $\mathrm{Mg}$ & 2 & 100 & 0.06060606 \\
\hline $\mathrm{Cl}$ & 2 & 350 & 0.06060606 \\
\hline $\mathrm{SO} 4$ & 4 & 400 & 0.12121212 \\
\hline $\mathrm{TDS}$ & 4 & 500 & 0.12121212 \\
\hline $\mathrm{TSS}$ & 2 & 1000 & 0.06060606 \\
\hline $\mathrm{Na}$ & 2 & 200 & 0.06060606 \\
\hline $\mathrm{K}$ & 2 & 10 & 0.06060606 \\
\hline & $\sum w_{i}=33$ & & $\sum W_{i}=1.0$ \\
\hline
\end{tabular}

Table 2. Water quality classification

\begin{tabular}{|l|c|}
\hline \multicolumn{1}{|c|}{ Water quality } & WQI value \\
\hline Excellent & $<50$ \\
\hline Good water & $50-100$ \\
\hline Poor water & $100-200$ \\
\hline Very poor water & $200-300$ \\
\hline Water unsuitable for drinking & $>300$ \\
\hline
\end{tabular}


The measured WQI values are categorized into five categories, "excellent water" to "unsuitable drinking water" as seen in the Table 2.

\section{RESULTS AND DISCUSSION}

In this study, the computed WQI values range from 85.4 to 99.17 for treated water and from 97.52 to 112.82 for raw water; therefore, treated water can be classified to the types "good water" and "poor water" for the raw water except three units were of "good water" classification. Table 3 shows the classification of the water samples that fall under different quality.

The fluctuation between the raw and treated water results can be imputed to the deterioration of the river water quality as a pollution consequence caused by the dropping of many kinds of pollutants into it except for the rejoins Al-Jimejma and Bermana where the quality of the River's water was good.

Table 3. Classification of water quality

\begin{tabular}{|c|c|c|c|}
\hline Unit & Water type & WQI & Quality \\
\hline \multirow{2}{*}{ Al-Taiara } & Treated & 96.07721 & good \\
\hline & Raw & 105.4049 & poor \\
\hline \multirow{2}{*}{ Al-Ataej } & Treated & 97.089 & good \\
\hline & Raw & 112.005 & poor \\
\hline \multirow{2}{*}{ Wardia } & Treated & 90.5269 & good \\
\hline & Raw & 112.8198 & poor \\
\hline \multirow{2}{*}{ Wardia2 } & Treated & 90.7401 & good \\
\hline & Raw & 102.6258 & poor \\
\hline \multirow{2}{*}{ Athar Babil } & Treated & 88.0175 & good \\
\hline & Raw & 103.2054 & poor \\
\hline \multirow{2}{*}{ Muamera } & Treated & 99.17065 & good \\
\hline & Raw & 103.367 & poor \\
\hline \multirow{2}{*}{ Al-Nekhala } & Treated & 94.6682 & good \\
\hline & Raw & 100.2679 & poor \\
\hline \multirow{2}{*}{ Al-Dolab } & Treated & 94.5995 & good \\
\hline & Raw & 98.9433 & good \\
\hline \multirow{2}{*}{ Al-Ifar } & Treated & 96.8538 & good \\
\hline & Raw & 104.185 & poor \\
\hline \multirow{2}{*}{ Barnoon 1} & Treated & 85.4505 & good \\
\hline & Raw & 102.1244 & poor \\
\hline \multirow{2}{*}{ Annana2 } & Treated & 89.6432 & good \\
\hline & Raw & 103.0783 & poor \\
\hline \multirow{2}{*}{ Al-Jimejma } & Treated & 90.1534 & good \\
\hline & Raw & 97.5169 & good \\
\hline \multirow{2}{*}{ Bermana } & Treated & 85.40274 & good \\
\hline & Raw & 96.5321 & good \\
\hline \multirow{2}{*}{ Al-Hillah Al Mouahad } & Treated & 86.46293 & good \\
\hline & Raw & 102.371 & poor \\
\hline
\end{tabular}

This means the river in these areas is considered unpolluted, and the reason for this may be due to the lack of pollutants being damped into the river in these areas since there is no industrial activity and consequently to the non-disposal of large quantities of pollutants to the river.

The study indicated as shown in the Table 4 of the rates of the studied variables in the river and complex (compact) units that there is a noticeable increase in the concentration of EC and TDS over the permissible limits in the raw (untreated) river water, which leads to an increase in the values of the water quality index in the river, while the rest of the variables were within the permissible limits. Moreover, it was noted that most of the treatment processes are done are to remove turbidity from the water. As for the rest of the other variables, the changes that occurred to them were so slight that they could hardly be noticed for both of the compact units and Al-Hillah Al Mouahad Project.

\section{CONCLUSIONS}

The study revealed that the water produced from the water purification complexes is comparable in quality to the water produced from the unified Hillah water project (Al-Hillah Al Mouahad Project), and it was of good quality according to the classification of the drinking water quality index. It is possible to use and benefit from the installation of such complexes for the service of small and remote areas. The study also concluded that the Euphrates River water at Shatt Al-Hillah and this obvious through the values of the WQI of raw water is of poor quality, as the river suffer from pollution as a result of throwing some industrial and agricultural wastes, sewage water, and the residues of the Big Hillah mallet. The study indicates that the river needs a degree of attention and further concern before use, and that it still needs to be secured from the pollution hazards.

\section{REFERENCES}

1. Al-Mansori N.J. 2017. Develop and Apply Water Quality Index to Evaluate Water Quality of ShattAl-Hilla River. Journal of Babylon University/Engineering Sciences, 25(2), 368-374.

2. Al Saleh Hadeel A. 2014. Assessment of Water Quality Index for Euphrates River Within Babylon 
Table 4. The rates of the studied variables in the river and complex (compact) units.

\begin{tabular}{|c|c|c|c|c|c|c|c|c|c|c|c|c|c|c|}
\hline Complex & $\begin{array}{l}\text { Water } \\
\text { type }\end{array}$ & TUR & $\mathrm{pH}$ & EC & ALK & $\mathrm{TH}$ & $\mathrm{Ca}$ & $\mathrm{Mg}$ & $C L$ & $\mathrm{SO}_{4}$ & TDS & TSS & $\mathrm{Na}$ & $\mathrm{K}$ \\
\hline \multirow{2}{*}{ Al-Taiara } & Dom & 16.8 & 8.1 & 1118.6 & 123.8 & 93.3 & 101.2 & 34.1 & 113.1 & 234.4 & 99.3 & 3.8 & 75 & 1.8 \\
\hline & Treated & 7.8 & 7.9 & 1123.9 & 119.6 & 397.2 & 100.2 & 36 & 112.6 & 209.6 & 693 & 66.6 & 74.3 & 1.8 \\
\hline \multirow{2}{*}{ Al-Ataej } & Raw & 23.1 & 8.1 & 1114.7 & 121.6 & 378.2 & 97.4 & 32.7 & 111.4 & 219.5 & 716.2 & 66.5 & 67 & 1.7 \\
\hline & Treated & 10.9 & 7.8 & 1116.5 & 118 & 378.3 & 96.6 & 33.1 & 111.1 & 222.5 & 739.3 & 58.4 & 65.3 & 1.5 \\
\hline \multirow{2}{*}{ Wardia1 } & Raw & 24.5 & 8 & 1080.3 & 119.7 & 395.9 & 101.3 & 35 & 107.7 & 191.7 & 730.4 & 62.9 & 75.5 & 1.7 \\
\hline & Treated & 7.4 & 7.8 & 1078.7 & 116.6 & 392.8 & 100.7 & 33.9 & 106.1 & 183.7 & 711.7 & 61.3 & 69.5 & 1.6 \\
\hline \multirow{2}{*}{ Wardia2 } & Raw & 13.7 & 8 & 1117.7 & 123.6 & 387.4 & 99.5 & 34.3 & 113.5 & 223 & 696.6 & 71 & 67.7 & 2 \\
\hline & Treated & 6.4 & 7.9 & 1115.8 & 119.4 & 387.4 & 86.9 & 33.1 & 114.4 & 222.8 & 695.3 & 51.5 & 66.7 & 2 \\
\hline \multirow{2}{*}{ Athar Babil } & Raw & 16 & 8.1 & 1090.5 & 122.6 & 391.1 & 98.4 & 35.5 & 108.6 & 235.6 & 684 & 71.1 & 72 & 1.9 \\
\hline & Treated & 4.5 & 7.8 & 1086.8 & 120.2 & 391 & 98.2 & 35 & 107 & 223.4 & 667.7 & 68.8 & 70.3 & 1.9 \\
\hline \multirow{2}{*}{ Muamera } & Raw & 10.4 & 8.1 & 1177.5 & 123 & 424.7 & 106.7 & 39.5 & 116.7 & 334 & 760.5 & 62.5 & 32 & 2.1 \\
\hline & Treated & 8 & 7.5 & 1165.5 & 116.5 & 420.5 & 105 & 37.5 & 109.5 & 308.5 & 753 & 55.5 & 80 & 2 \\
\hline \multirow{2}{*}{ Al-Nekhala } & Raw & 15.2 & 8.1 & 1060.7 & 121.3 & 381.8 & 98.3 & 33.2 & 106.9 & 218.8 & 683.1 & 71.7 & 66.5 & 1.6 \\
\hline & Treated & 11.8 & 7.7 & 1055.2 & 118.8 & 376.5 & 98.1 & 32 & 104 & 218.4 & 668.1 & 53.3 & 65 & 1.5 \\
\hline \multirow{2}{*}{ Al-Dolab } & Raw & 16.2 & 8.1 & 1109.2 & 121.1 & 394.9 & 100.1 & 35.2 & 109.9 & 227.1 & 696.8 & 78 & 65 & 1.5 \\
\hline & Treated & 9.7 & 7.8 & 1107.8 & 117.8 & 394.1 & 99.6 & 35.2 & 109.8 & 226 & 684.6 & 54.7 & 65 & 1.5 \\
\hline \multirow{2}{*}{ Al-Ifar } & Raw & 12 & 8.1 & 1136.3 & 119.3 & 413.6 & 107 & 35.3 & 114.3 & 334.3 & 715.3 & 66 & 80 & 2.1 \\
\hline & Treated & 7.4 & 7.7 & 1135.6 & 114 & 409.3 & 105.6 & 35.3 & 113.3 & 316 & 703.3 & 60.7 & 81 & 2.1 \\
\hline \multirow{2}{*}{ Barnoon1 } & Raw & 13.6 & 8.1 & 1079.6 & 125.2 & 405.1 & 97.8 & 39.3 & 113.3 & 242.3 & 710 & 66.4 & 79.3 & 2.4 \\
\hline & Treated & 6.9 & 7.8 & 1070.5 & 120.2 & 404.3 & 97.5 & 39.1 & 118.1 & 234.2 & 686.6 & 57.6 & 74.3 & 2.3 \\
\hline \multirow{2}{*}{ Annana2 } & Raw & 14.8 & 8 & 1115.4 & 120.4 & 398.4 & 97 & 38.3 & 113.8 & 256.7 & 714.8 & 65.3 & 69.5 & 1.6 \\
\hline & Treated & 4.4 & 7.7 & 1108.4 & 120 & 388.8 & 96.4 & 35.6 & 110.5 & 255.9 & 710.7 & 45.5 & 69 & 1.6 \\
\hline \multirow{2}{*}{ Al-Jimejma } & Raw & 12.1 & 8.1 & 1083.1 & 120.5 & 392.1 & 104.2 & 34.3 & 110.7 & 211.6 & 688.5 & 66.7 & 61 & 1.9 \\
\hline & Treated & 6.8 & 7.7 & 1082.6 & 120 & 391.8 & 101.5 & 33.5 & 110.5 & 211.1 & 686.5 & 59 & 58.5 & 1.9 \\
\hline \multirow{2}{*}{ Bermana } & Raw & 12.1 & 7.9 & 1074.5 & 121.5 & 386.5 & 93 & 37.5 & 112.8 & 222 & 666.5 & 80.9 & 67.5 & 1.6 \\
\hline & Treated & 3.8 & 7.9 & 1070 & 119 & 384 & 92.8 & 36.7 & 111.3 & 205.5 & 659 & 66.3 & 67 & 1.6 \\
\hline
\end{tabular}

Province, Iraq During the Period 2007-2013. International Journal of Civil Engineering and Technology, 5(5), pp. 41-50.

3. Ali M.H.H., Al-Qahtani K.M., Alturiqi A.S., Albedair L.A., Alibrahim K.A. 2012. Estimation of Water Quality Index and Assessment of Some Heavy Metals in potable water at Kingdom Saudi Arabia. Journal of Applied Sciences Research, 8(7), 3206-3210.

4. Rahi K.A. and Halihan T. 2010. Changes in the Salinity of the Euphrates River System in Iraq. Regional Environment Change, 10(1), 27-35.

5. Ramakrishnaiah C.R., Sadashivaiah C., Ranganna G. 2009. Assessment of Water Quality Index for The Groundwater in Tumkur Taluk, Karnataka State, India. E-Journal of Chemistry, 6(2), 523-530.
6. Simoes F.S., Moreira A.B., Bisinoti M.C., Gimenez S.M.N., Yabe M.J.S. 2008. Water Quality Index as a Simple Indicator of Aquaculture Effects on Aquatic Bodies. Ecological Indicators, 8(5), 476484.

7. Toma J. J. 2013. Evaluating Raw and treated water quality of Greater Zab River within Erbil city by index analysis. International Journal of Emerging Technologies in Computational and Applied Sciences, 3(2), 147-154.

8. Tyagi S., Sharma B., Singh P., Dobhal R. 2013. Water quality assessment in terms of water quality index. American Journal of Water Resources, 1(3), 34-38.

9. US EPA, 2009. Environmental impact and benefits assessment for final effluent guidelines and standards for the construction and development category. Office of Water, Washington, DC. EPA- 821-R-09-0 